\title{
THE RESULTS OF EVALUATION OF DYNAMICS OF LEVELS OF GLYCEMIA IN DIABETES MELLITUS TYPE 1
}

E. Makhlina, Y. Navmenova*, E. Kholodova**, T. Mokhort**

SI Republican Research Centre for Radiation Medicine and Human Ecology, Gomel State Medical University*, Belarusian State Medical University**

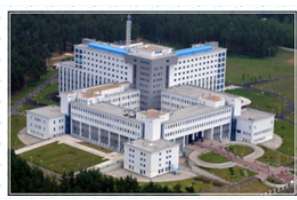

The aim of the work was to assess the dynamics of rates of carbohydrate metabolism in diabetes mellitus type 1 (DMT1) in young persons.

Materials and methods. The study of daily dynamics of glucose was conducted by Continuous Glucose Monitoring System (CGMS) of MedtronikMINIMED Company, USA. Standard glucose profile (4-5 per day) was measured in capillary blood by glucometer «Finetest ${ }^{\mathrm{TM}}$, Infopia Co., Ltd. For the analysis of continuous glycemic curve there was conducted the computation of risk index (RI) of hypoglycemia and hyperglycemia during the study period.

There were examined 162 patients with DMT1. First group with adequate control DMT1, HbA1c $\leq 7,5 \%(n=38)$, which is $23 \%$ and second group with inadequate control, HbA1c> 7,5\% $(n=124)$, which is $77 \%$ of the total number of examined persons.

Clinical characteristics of the examined persons depending on hypoglycemic episodes manifestation Me

\begin{tabular}{|l|c|c|c|}
\hline & $1^{\text {st }}$ Group & $2^{\text {nd }}$ group & P \\
\hline Age , years & with HbA1c $\leq 7,5 \%(\mathbf{n}=38)$ & with HbA1c > 7,5\% $(\mathbf{n}=124)$ & 0,388 \\
\hline Duration of T1DM, years & $29,81[25,84 ; 35,26]$ & $28,73[21,94 ; 36,04]$ & 0,289 \\
\hline Body mass index, kg/M2 & $7,71[2,98 ; 13,53]$ & $8,52[3,89 ; 14,22]$ & 0,541 \\
\hline Weight, kg & $23,64[21,46 ; 26,00]$ & $23,73[21,96 ; 26,14]$ & 0,273 \\
\hline Number of SU per day & $68,50[57,50 ; 77,00]$ & $65,00[58,00 ; 76,00]$ & 0,313 \\
\hline Day dose of insulin, IU/day & $16,00[13,00 ; 19,00]$ & $17,00[14,00 ; 19,00]$ & 0,001 \\
\hline
\end{tabular}

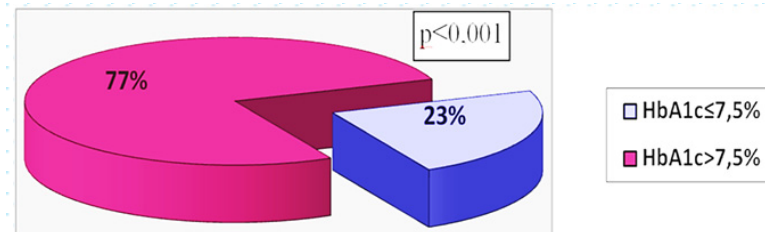
Adequate control of DMT1 was only in $23 \%$ of examined patients, in $77 \%$ there has been noticed decompensation of DMT1 ( $p<0,05)$

In the group with $\mathrm{HbA1C}>7,5 \%$ there has been noticed decompensation of DMT1 due posthypoglycemic hyperglycemia (RI of hypoglycemia 5,00 [ 1,$60 ; 9,20$ ], RI of hyperglycemia $16,24[10,45 ; 20,60]$ ). In both groups Rl of hypoglycemia exceeded 4,5 (group with $\mathrm{HbA} 1 \mathrm{c} \leq 7,5 \% 5,60[3,00 ; 10,50]$, group with $\mathrm{HbA1c}>7,5 \% 5,00[1,60 ; 9,20])$, which indicate a high risk of development of hypoglycemic reactions.

Average glucose, $\mathrm{mmol} / \mathrm{l}$

Minimum glucose, $\mathrm{mmol} / \mathrm{l}$

Maximum glucose, $\mathrm{mmol} / \mathrm{l}$

RI of hypoglycemia

RI of hyperglycemia $1^{\text {st }}$ Group with HbA1c $\leq 7,5 \%$

$8,15[6,90 ; 10,00]$

$2,30[2,20 ; 2,80]$

$17,25[15,10 ; 19,60]$

$5,60[3,00 ; 10,50]$

$8,25[4,80 ; 14,70]$ $2^{\text {nd }}$ group with $\mathrm{HbA1C}>7,5 \%$

$10,40[8,90 ; 12,70]$

$2,80[2,20 ; 4,20]$

$20,30[17,70 ; 22,20]$

$5,00[1,60 ; 9,20]$

$16,24[10,45 ; 20,60]$
P

$<0,001$

0,004

$<0,001$

0,406

0,001

In the group with adequate control hypoglycemic episodes have been registered in $82 \%$ of the patients and only $18 \%$ didn't have them ( $p<$ 0,001 ). In decompensation of DMT1 hypoglycemic reactions had $55 \%$ of patients, and in $45 \%$ of patients they have not been registered $(p>0,05)$.

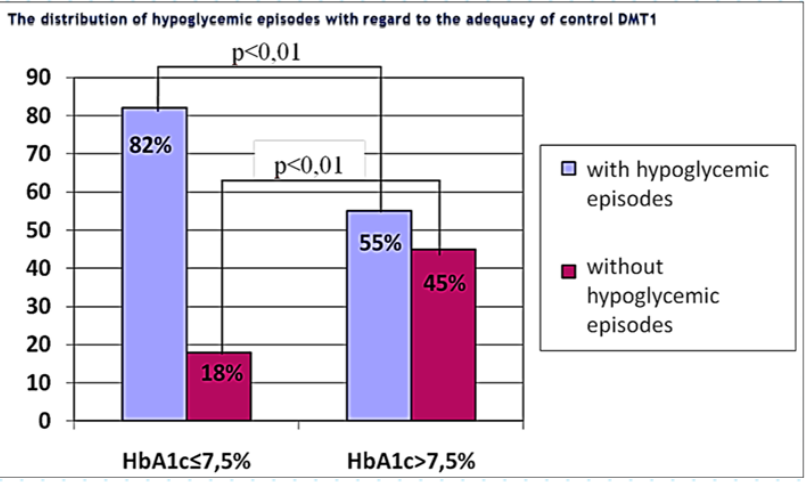

CONCLUSION: In $77 \%$ of the examined patients with DMT1 there have not been achieved target values of compensation, which is approved by the increased value of RI hypoand hyperglycemia. Decompensation of DMT1 is caused by posthypoglycemic hyperglycemia. Regardless of the DMT1 control adequacy there has been marked a high risk of hypoglycemic reactions (RI hypoglycemia more than 4,5$)$. 